\title{
Trabeculectomy with Suprachoroidal Derivation in Eyes with Uncontrolled Glaucoma: A Case Series with a 24-Month Follow-up
}

\author{
Rodolfo A. Perez-Grossmann · Daniel E. Grigera · Alan Wenger
}

Received: January 4, 2019 / Published online: March 16, 2019

(C) The Author(s) 2019

\section{ABSTRACT}

Introduction: The aim of this study was to evaluate the efficacy of trabeculectomy with suprachoroidal derivation in eyes with uncontrolled glaucoma after a 24-month follow-up period.

Methods: This was a prospective uncontrolled non-randomized case series. All patients scheduled for a trabeculectomy due to uncontrolled glaucoma at the "Instituto de Glaucoma y Catarata" (Lima, Peru) between 2011 and 2014 were included. Thee patients underwent trabeculectomy with mitomycin $\mathrm{C}$ and suprachoroidal derivation with two autologous scleral flaps. Postsurgical follow-up visits took place on day 1 , and at 1, 6, 12, 18 and 24 months. Best corrected visual acuity (BCVA), intraocular pressure (IOP) and complications at each control were registered. Main outcome measures were IOP

Enhanced digital features To view enhanced digital features for this article go to https://doi.org/10.6084/ m9.figshare.7813496.

R. A. Perez-Grossmann ( $\square)$

Instituto de Glaucoma y Catarata, Lima, Peru

e-mail: raperezg@glaucomaperu.org

D. E. Grigera

Glaucoma Service, Hospital Oftalmológico Santa

Lucía, Buenos Aires, Argentina

A. Wenger

Glaucoma Service, Hospital San Juan de Dios,

Santiago, Chile reduction, number of glaucoma medications and complication rate. Postoperative IOP of $>21 \mathrm{mmHg},<5 \mathrm{mmHg}$, additional glaucoma surgery or severe complications were considered as indications of failure.

Results: Thirty-three participants (41 eyes) were included in the study, of whom 27 $(81.82 \%)$ (31 eyes [75.61\%]) finished the 24 months of follow-up. At the end of the follow-up, mean IOP had decreased by $11.29 \pm 9.32 \mathrm{mmHg}(p<0.001)$, and glaucoma medication usage in $25(25 / 31 ; 80.65 \%)$ eyes had stopped. Ten $(10 / 41 ; 24.39 \%)$ patients complained of blurred vision, and 15 (15/41; $36.59 \%)$ patients referred to foreign body sensation the first day after surgery; both sensations resolved spontaneously after 1 week in all cases. No failures, significant changes in BCVA ( $p=0.387$ ) or severe complications were found. Conclusions: In this case series, trabeculectomy with suprachoroidal derivation exhibited high efficacy and safety after a 24-month follow-up. A larger sample with a control group is needed to confirm our initial findings.

Keywords: Follow-up studies (MeSH); Glaucoma; Trabeculectomy; Treatment outcome 


\section{INTRODUCTION}

Glaucoma is one of the leading causes of blindness in the world and is expected to affect 80 million people globally by 2020 [1-3]. Although medical therapy is common as initial treatment, current evidence suggests that surgical treatment may be equal or superior to medical therapy when indicators such as intraocular pressure (IOP), quality of life and visual field loss are taken into consideration [4-7].

Trabeculectomy is not commonly used as the first line of treatment, but its use, concomitant with drainage devices, is predominant in eyes resistant to medical treatment and laser therapy. Although these interventions are frequently successful, they are associated with fibrosis and various complications, such as infections or hypotonia [8-11]. Likewise, a large number of postoperative medications to maintain adequate IOP control is frequently needed. [12].

Here, we report our evaluation of the efficacy of a new procedure, consisting of a trabeculectomy with mitomycin $\mathrm{C}$ together with suprachoroidal derivation with two autologous scleral flaps, designed to avoid the difficulties commonly associated with trabeculectomy.

\section{METHODS}

The study was approved by the Institutional Review Board of our institute (Instituto de Glaucoma y Catarata) and was based on information collected from our clinical practice. Patient consent for undergoing the procedure and for the use of images was obtained and registered. The case series is not registered in a trial registry database because it is based on information collected form our clinical practice and thus is considered to be an observational study. All procedures followed were in accordance with the Declaration of Helsinki of 1964, as revised in 2013.

This is a prospective, uncontrolled, nonrandomized case series. All patients scheduled for a trabeculectomy at the "Instituto de Glaucoma y Catarata" (Lima, Peru) between August
24, 2011 and February 6, 2014 were included, with the exception of patients with neovascular glaucoma, those scheduled for a secondary glaucoma vitreous retinal surgery and those who did not wish to undergo a new surgical technique. Informed consent was obtained from all individual participants asked to take part in this study.

Follow-up visits were scheduled on day 1 and on months 1, 6, 12, 18 and 24 .

All patients underwent slit-lamp examination, gonioscopy and ultrasound biomicroscopy (UBM) of the anterior segment. A VuMax (Sonomed Escalon, New Hyde Park, NY, USA) UBM device was used to obtain radial scans through the central axis of the surgical area at all visits.

Best corrected visual acuity (BCVA) was expressed in LogMAR, intraocular pressure (IOP) was measured with a Goldmann applanation tonometer and complications were registered at each control. The main outcome measures were IOP reduction, number of glaucoma medications and complication rate. Each hypotensive agent, either administered alone or in a fixed combination with others, was considered to be a single glaucoma medication.

The statistical analysis was performed using STATA v14 (StataCorp LP, College Station, TX, USA) utilizing a paired Wilcoxon signed-rank test for IOP reduction, number of medications and BCVA analysis ( $p<0.05$ was to be considered statistically significant).

\section{Surgical Procedure}

All surgical procedures were performed by the same surgeon (RAPG). The procedure is performed under topical and subconjunctival anesthesia (proparacaine hydrochloride 0.5\% and $0.5 \mathrm{cc}$ lidocaine $2 \%$, respectively). If there have been previous surgeries, the upper quadrant that presents less fibrosis is chosen as the site.

The surgeon makes a fornix-based conjunctival incision of approximately $6 \mathrm{~mm}$ with relaxing incisions at the ends. A complete, blunt Tenon dissection with slight cauterization of episcleral vessels allows an optimal exposure 
and visualization of the operative area. A square scleral flap $(5 \mathrm{~mm}$ per side; thickness $=50 \%$ of the sclera, until clear cornea is reached) is then created using a crescent knife. Mitomycin C $(0.4 \mathrm{mg} / \mathrm{mL}$ for $3 \mathrm{~min})$ is applied onto the operative area, under conjunctiva and Tenon's capsule, using microsponges, followed by abundant washing of the area with saline solution. This is followed by a second, deeper limbus-based scleral flap of $4 \times 3 \times 4 \mathrm{~mm}$, and $30 \%$ of the scleral thickness is removed, leaving $1 \mathrm{~mm}$ of free space on each side of the previous flap. The deep flap is then divided radially, with two cuts, in three parts of $1-\mathrm{mm}$ width each, and then the central part is removed, leaving two lateral portions.

The following step is to make a $3-\mathrm{mm}$ transversal incision in the remaining $20 \%$ of the sclera, until the choroid is reached, carefully dissecting a suprachoroidal channel with a blunt spatula. This incision is made at approximately $3 \mathrm{~mm}$ from the limbus, using a $2-\mathrm{mm}$ Crescent Blade. A bite with the 0.9-mm Kelly Punch is then made at the center of the posterior lip of the scleral incision, followed by paracentesis (Fig. 1).

The lateral flaps are then inserted into each side of the suprachoroidal space (SCS), forming a channel that will lead the aqueous humor from the anterior chamber intothe SCS (Fig. 2).

The trabeculectomy is performed next. A 1 -mm penetrating incision is made at the limbus (base of the second scleral flap) with a

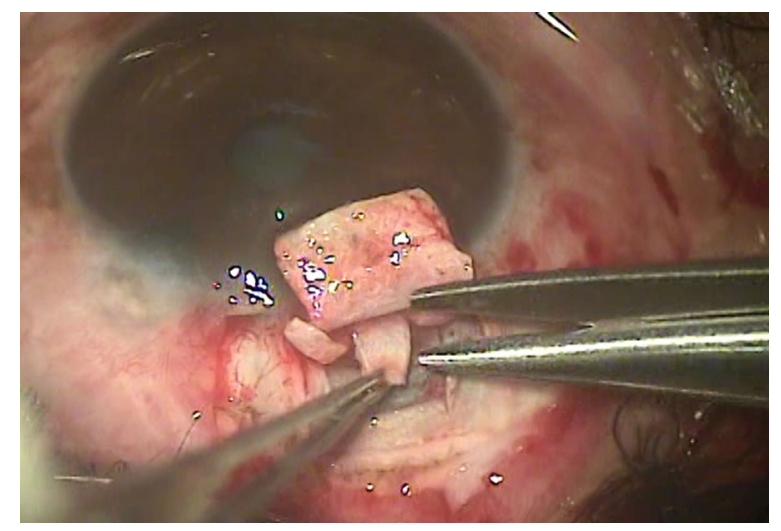

Fig. 1 The inner flap was divided into three 1-mm flaps through the longest axis and then the 1-mm central flap was removed

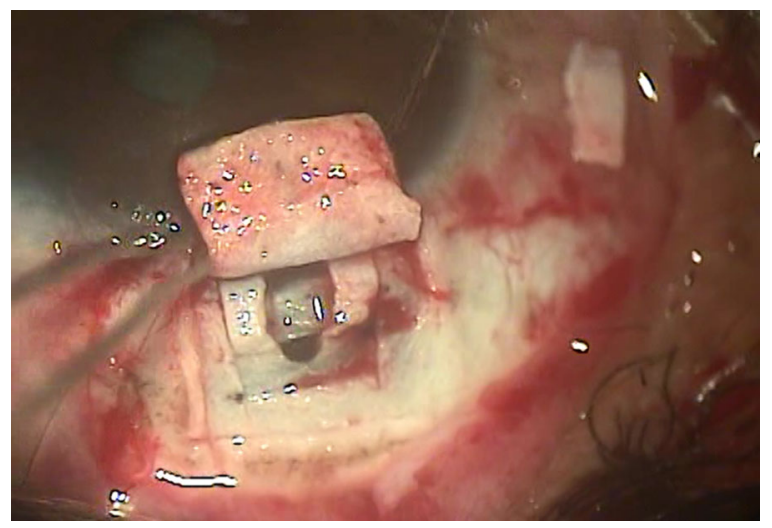

Fig. 2 The ends of the two lateral flaps are inserted in the suprachoroidal space (SCS), forming a channel to direct the aqueous humor from the anterior chamber to the SCS

sideport knife, followed by a bite with the 0.9mm Kelly Punch and a basal iridectomy with Vannas scissors, resulting in communication between the anterior chamber and the scleral channel. The first scleral flap is tightly sutured with nylon 10-0 ( 2 stitches in each of the 3 sides of the flap). This flap forms the roof of the tunnel. Finally, the conjunctiva is sutured with nylon 10/0.

The postoperative medication is a combination of moxifloxacin $0.5 \%$ /dexametasone $0.1 \%$ eyedrops, 6 times a day for the first week, 4 times a day for the second week and prednisolone acetate 1\%, 3 times a day for 4 weeks.

\section{RESULTS}

Thirty-three participants (41 eyes) were included in the study, of whom 27 patients $(77.14 \%)$ finished the 24-month follow-up. Six patients missed a significant number of control visits or did not attend the final visit. Thus, 31 eyes (75.61\%) completed the study (Table 1 ).

We found no significant demographic differences between the presurgical and postsurgical participants. Ten $(10 / 31 ; 32.26 \%)$ eyes had not undergone any previous intraocular procedures, and all patients were using glaucoma medications. Mean presurgical IOP was $23.23 \pm 8.61$ (range 13-56) $\mathrm{mmHg}$, mean number of preoperative glaucoma medications was $3.13 \pm 1.31$ (range 1-5) and mean 
Table 1 Demographics of study population

\begin{tabular}{|c|c|c|c|c|c|}
\hline \multirow[t]{2}{*}{ Demographics of study population } & \multicolumn{2}{|c|}{$\begin{array}{l}\text { Pre-surgery }(n=41 \text { eyes } / 33 \\
\text { participants) }\end{array}$} & \multicolumn{2}{|c|}{$\begin{array}{l}\text { Post follow-up ( } 24 \text { months })(n=31 \\
\text { eyes } / 27 \text { participants })\end{array}$} & \multirow[t]{2}{*}{$p$} \\
\hline & $n$ & $\%$ & $n$ & $\%$ & \\
\hline Sex & & & & & 0.480 \\
\hline Male & 17 & 51.52 & 15 & 55.56 & \\
\hline Female & 16 & 48.48 & 12 & 44.44 & \\
\hline Age (years) & 61.50 & 19.88 & 64.70 & 19.82 & 0.657 \\
\hline Lens status & & & & & 0.470 \\
\hline Phakic & 24 & 58.54 & 17 & 54.84 & \\
\hline Pseudophakic & 17 & 41.46 & 14 & 45.16 & \\
\hline Number of affected eyes & & & & & 0.282 \\
\hline 1 & 25 & 75.76 & 23 & 85.19 & \\
\hline 2 & 8 & 24.24 & 4 & 14.81 & \\
\hline Glaucoma type & & & & & 1.000 \\
\hline POAG & 30 & 73.17 & 22 & 70.97 & \\
\hline PCAG & 2 & 4.88 & 2 & 6.45 & \\
\hline NTG & 1 & 2.44 & 1 & 3.23 & \\
\hline Juvenile glaucoma & 5 & 12.20 & 3 & 9.68 & \\
\hline Pseudoexfoliative glaucoma & 2 & 4.88 & 2 & 6.45 & \\
\hline Pigmentary glaucoma & 1 & 2.44 & 1 & 3.23 & \\
\hline
\end{tabular}

Data are presented as the number of patients, with the exception of Age which is presented as the mean $N T G$ Normal-tension glaucoma, $P C A G$ primary closed-angle. glaucoma, $P O A G$ primary open-angle glaucoma

preoperative BCVA in LogMAR was $0.30 \pm 0.32$ (range -0.10 to 1 ). According to the Enhanced Glaucoma Staging System (GSS2) [13], basal functional damage was Stage 5 in 17 eyes (41.46\%), Stage 4 in 12 eyes (29.27\%), Stage 3 in four eyes $(9.76 \%)$, Stage 2 in five eyes $(12.20 \%)$, Stage 1 in one eye (2.44\%) and Stage 0 in 2 eyes $(4.88 \%)$.

At the end of the follow-up period (24 months), mean IOP was $11.94 \pm 2.43$ (range 7-16) $\mathrm{mmHg}$, mean number of glaucoma medications was $0.42 \pm 0.96$ (range 0-4) and mean BCVA in LogMar was $0.29 \pm 0.54$ (range 0-3) (Fig. 3). Mean IOP decrease from baseline values was $11.29 \pm 9.32 \mathrm{mmHg}(p<0.001)$, a reduction of $48.60 \%$. We found a significant reduction in mean glaucoma medication usage $(p<0.001)$, with $25(25 / 31 ; 80.65 \%)$ eyes having stopped glaucoma medication usage due to target IOP being achieved $(p<0.001)$. Thirty $(96.77 \%)$ patients had an IOP of $\leq 15 \mathrm{mmHg}$ after the follow-up. We found no failures or significant changes in BCVA $(p=0.387)$ at the end of follow-up. Previous eye surgery did not affect IOP reduction $(p=0.687)$.

The filtration bleb observed was moderate, diffuse and posterior, showing minimal anatomical changes in the controls. When ultrasound biomicroscopy was performed, a patent ostium and wide aqueous pathway underneath the scleral flap was noted, with an 


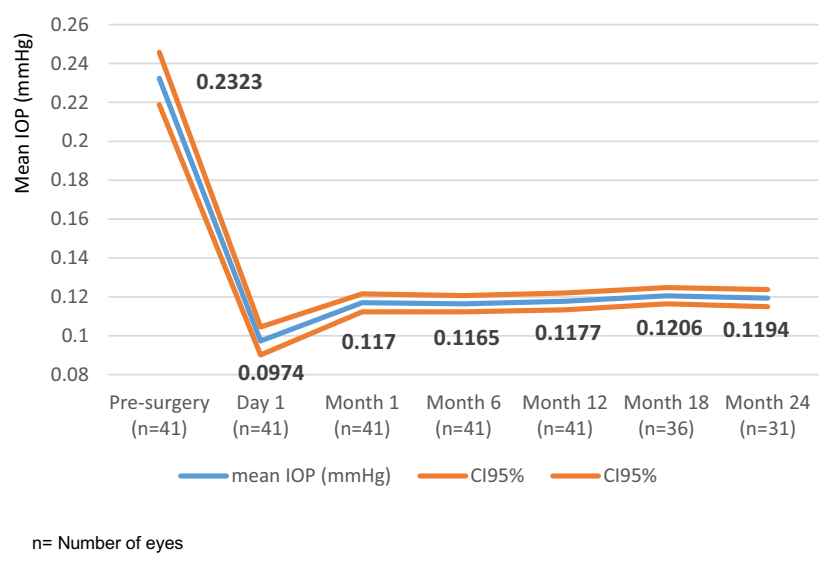

Fig. 3 Mean intraocular pressure $(I O P)$ over the 24-month follow-up period. CI Confidence interval

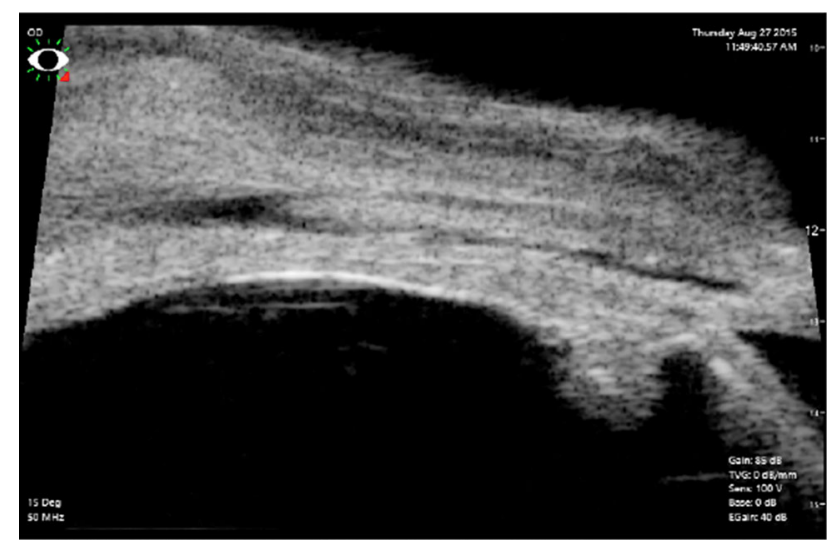

Fig. 4 The scleral flap is visible and is evident in the suprachoroidal space, as shown in the ultrasound biomicroscopy. A subconjunctival space is also present

evident suprachoroidal and subconjunctival space (Fig. 4).

Ten $(10 / 41 ; 24.39 \%)$ patients complained of blurred vision and 15 (15/41; 36.59\%) referred foreign body sensation the first day after surgery. Both symptoms had subsided spontaneously after 1 week in all cases. No severe complications were found.

\section{DISCUSSION}

The wound-healing process remains the greatest determinant of success in glaucoma filtration surgery, as complications occurring during this process may impair IOP control, worsen the prognosis and/or cause progression of disc cupping and visual field loss [14]. Eyes in which trabeculectomy has failed have a higher risk of further failure with subsequent filtering surgeries, including drainage devices [8-11, 15]. The use of mitomycin $\mathrm{C}$ and 5-fluorouracil improves the success rate, but also increases the risk of complications [10, 15-17].

Unlike classic trabeculectomy, our surgical procedure has the advantage of using two different drainage pathways to lower the IOP: the anterior chamber to subconjunctival space fistula and the uveoscleral drainage through the SCS. If the filtration bleb becomes increasingly vascularized and/or excessive capsular fibrosis appears, the uveoscleral pathway may be still patent.

The pathophysiological basis of bleb scarring appears to be related to exposure to aqueous 
humor that contains a higher concentration of inflammatory mediators, which in turn can activate a fibrotic response after contact with vascular Tenon tissue $[18,19]$. In our technique, the intrascleral pathway does not come into contact with vascular Tenon tissue, raising the expectation that a fibrotic response will not be activated and indeed may remain patent. Another point to consider in the generation of fibrosis is the location of the drainage route. Previous studies suggest that the SCS may have a lower frequency of fibrosis compared to the subconjunctival space due to differences in cell proliferation [20].

The suprachoroidal surgical approach has other factors that led us to select it, such as the clinically relevant choroidal resorptive function, the negative difference in hydrostatic pressure and the natural counterpressure of the SCS. Our search of the literature found evidence that these factors may counteract the appearance of hypotony while maintaining aqueous drainage $[14,21,22]$. Also, the SCS is an attractive route of drug delivery, bypassing the sclera and diffusing rapidly into the posterior segment [23]. This may be specially useful in patients with uveitic glaucoma and retinal diseases associated with macular edema for whom it is hard to maintain therapeutic drug concentrations [24].

Our intervention is not the only one that has used the SCS as a filtration pathway; a number of previous studies have used this approach with varying degrees of success. These interventions use different devices, such as modified tubes or complex devices, that are inserted into the SCS, such as, for example, the Gold Micro Shunt (SOLX Ltd, Boston, MA, USA) and the CyPass Micro-Stent (Alcon, Fort Worth, TX, USA). Compared to standard trabeculectomy, the success rate of some of these procedures has been shown to be higher than that of trabeculectomy, with differences varying between 10 and $30 \%$. Also, the frequency of complications appears to be approximately $20 \%$ lower $[14,15,25-28]$. When we evaluated the intervention against other procedures employing suprachoroidal devices, we observed that those surgeries present a success rate of approximately
$70-90 \%$ compared to nearly $100 \%$ in our technique.

The present intervention has unique characteristics because it uses the SCS without resorting to devices designed to maintain it. One important advantage is that it uses only scleral tissue from the patient's own eye. Another important advantage is the long follow-up and evidence of the maintenance of the mentioned space over time. A complete success rate, defined as controlled IOP without additional medications remained high during the follow-up (80.65\%) as compared to other interventions $[14,15,25-28]$.

The procedure described in our study offers multiple advantages. By using autologous scleral tissue, there is a tendency to avoid rejection as well as the risk of fibrotic reaction consecutive to the presence of a foreign body. The location of the suprachoroidal incision, above the pars plana, may tend to decrease the risk of cyclodialysis, as well as that of severe intraoperative and postoperative hemorrhages. During the follow-up period we did not observe any bleb-related complications or surgical failure secondary to subconjunctival fibrosis [29]. The use of an aqueous conductive channel totally formed by sclera may have some advantages over the episcleral devices, including the lack of conjunctival erosions, lower risk of endophthalmitis secondary to explant exposition and absence of damage to the extraocular muscles $[24,30]$.

In addition, as this procedure does not depend exclusively on the filtrating bleb it can be performed in eyes in which the conjunctival scarring would not allow a conventional filtration surgery [31]. Another advantage is that in our procedure there are no foreign bodies in the anterior chamber, thereby avoiding contact complications such as corneal decompensation and cataracts [31].

The report of surgical complications is quite heterogeneous among studies. Despite these differences, the overall frequency of complications is higher in standard trabeculectomy than in interventions using suprachoroidal devices $[8,11,18]$. In our study, the frequency of complications was low, even in comparison with similar interventions $[9,25-28]$, with no 
serious complications or challenging situations, such as infections or prolonged hypotony.

We found that the IOP was significantly reduced in all patients and that most patients were able to stop glaucoma medication usage after the 24 months of follow-up. In patients who required medical treatment, the number of different medications decreased significantly, the majority ultimately only using a single drug. Patients' visual acuity was not affected by the procedure, and no permanent or severe complications were observed.

We have included some operated cases of both eyes with this technique. It can be argued that the fellow eyes are not independent because they may share success/failure factors. We acknowledge this point as a potential limitation.

A limitation of the procedure is its long learning curve, due to the complexity of performing the two scleral flaps and creating a patent tunnel. Despite this, we believe that the advantages of the procedure far outweigh this limitation. Despite having a significant loss of follow-up, we do not believe that this has affected the end results of the study. The followup at 12 months did not present losses and had comparable results. Also, the demographic characteristics of the patients at the beginning and end of the study were similar. While the number of participants in this study is higher than those used in similar studies, it is still insufficient to obtain definitive results.

\section{CONCLUSIONS}

In this case series, trabeculectomy with suprachoroidal derivation exhibits high efficacy and safety after a 24-month follow-up. A larger sample with a control group is needed to confirm our initial findings.

\section{ACKNOWLEDGEMENTS}

The authors thank the participants of the study.
Funding. No funding or sponsorship was received for this study or publication of this article. The article processing charges were funded by the authors.

Authorship. All named authors meet the International Committee of Medical Journal Editors (ICMJE) criteria for authorship for this article, take responsibility for the integrity of the work as a whole, and have given their approval for this version to be published.

Disclosures. Rodolfo Pérez-Grossmann, Daniel E. Grigera and Alan Wenger have nothing to declare.

Compliance with Ethics Guidelines. The study was approved by the IRB of our institute (Instituto de Glaucoma y Catarata). All procedures followed were in accordance with the Declaration of Helsinki of 1964, as revised in 2013. Informed consent was obtained from all the participants in this study.

Data Availability. The datasets during and/ or analyzed during the current study are available from the corresponding author on reasonable request.

Open Access. This article is distributed under the terms of the Creative Commons Attribution-NonCommercial 4.0 International License (http://creativecommons.org/licenses/ by-nc/4.0/), which permits any noncommercial use, distribution, and reproduction in any medium, provided you give appropriate credit to the original author(s) and the source, provide a link to the Creative Commons license, and indicate if changes were made.

\section{REFERENCES}

1. World Health Organization. The world health report 2003: shaping the future. Geneva: World Health Organization; 2003.

2. Quigley HA, Broman AT. The number of people with glaucoma worldwide in 2010 and 2020. Br J Ophthalmol. 2006;90(3):262-7. 
3. Kingman S. Glaucoma is second leading cause of blindness globally. Bull World Health Organ. 2004;82:887-8.

4. Lichter PR, Musch DC, Gillespie BW, et al. Interim clinical outcomes in the Collaborative Initial Glaucoma Treatment Study comparing initial treatment randomized to medications or surgery. Ophthalmology. 2001;108(11):1943-53.

5. Janz NK, Wren PA, Lichter PR, et al. The Collaborative Initial Glaucoma Treatment Study: interim quality of life findings after initial medical or surgical treatment of glaucoma. Ophthalmology. 2001;108(11):1954-65.

6. Burr J, Azuara-Blanco A, Avenell A, Tuulonen A. Medical versus surgical interventions for open angle glaucoma. Cochrane Database Syst Rev. 2012;9:CD004399.

7. Boland MV, Ervin A-M, Friedman DS, et al. Comparative effectiveness of treatments for open-angle glaucoma: a systematic review for the US Preventive Services Task Force. Ann Intern Med. 2013;158(4):271-9.

8. Olayanju JA, Hassan MB, Hodge DO, Khanna CL. Trabeculectomy-related complications in Olmsted County, Minnesota, 1985 through 2010. JAMA Ophthalmol. 2015;133(5):574-80.

9. Jampel HD, Musch DC, Gillespie BW, Lichter PR, Wright MM, Guire KE. Perioperative complications of trabeculectomy in the collaborative initial glaucoma treatment study (CIGTS). Am J Ophthalmol. 2005;140(1):16-22.

10. DeBry PW, Perkins TW, Heatley G, Kaufman P, Brumback LC. Incidence of late-onset bleb-related complications following trabeculectomy with mitomycin. Arch Ophthalmol. 2002;120(3):297-300.

11. Picht G, Mutsch Y, Grehn F. Follow-up of trabeculectomy. Complications and therapeutic consequences. Ophthalmol Z Dtsch Ophthalmol Ges. 2001;98(7):629-34.

12. Gedde SJ, Schiffman JC, Feuer WJ, et al. Three-year follow-up of the tube versus trabeculectomy study. Am J Ophthalmol. 2009;148(5):670-84.

13. Brusini P, Filacorda S. Enhanced Glaucoma Staging System (GSS 2) for classifying functional damage in glaucoma. J Glaucoma. 2006;15(1):40-6.

14. Jordan JF, Engels BF, Dinslage S, et al. A novel approach to suprachoroidal drainage for the surgical treatment of intractable glaucoma. J Glaucoma. $2006 ; 15(3): 200-5$.
15. Unal M, Kocak Altintas AG, Koklu G, Tuna T. Early results of suprachoroidal drainage tube implantation for the surgical treatment of glaucoma. J Glaucoma. 2011;20(5):307-14.

16. Bindlish R, Condon GP, Schlosser JD, D'Antonio J, Lauer KB, Lehrer R. Efficacy and safety of mitomycin-C in primary trabeculectomy: five-year follow-up. Ophthalmology. 2002;109(7):1336-41.

17. Fontana H, Nouri-Mahdavi K, Caprioli J. Trabeculectomy with mitomycin $\mathrm{C}$ in pseudophakic patients with open-angle glaucoma: outcomes and risk factors for failure. Am J Ophthalmol. 2006;141(4):652-9.

18. Gedde SJ, Lee RK. Comparing glaucoma drainage implants. Am J Ophthalmol. 2010;149(6):875-7.

19. Epstein E. Fibrosing response to aqueous. Its relation to glaucoma. Br J Ophthalmol. 1959;43:641-7.

20. Hovakimyan M, Siewert S, Schmidt W, et al. Development of an experimental drug eluting suprachoroidal microstent as glaucoma drainage device. Transl Vis Sci Technol. 2015;4(3):14.

21. Francis BA, Singh K, Lin SC, et al. Novel glaucoma procedures: a report by the American Academy of Ophthalmology. 2011;118(7):1466-80.

Ophthalmology.

22. Emi K, Pederson JE, Toris CB. Hydrostatic pressure of the suprachoroidal space. Invest Ophthalmol Vis Sci. 1989;30(2):233-8.

23. Moisseiev E, Loewenstein A, Yiu G. The suprachoroidal space: from potential space to a space with potential. Clin Ophthalmol Auckl NZ. 2016;10:173-8.

24. Saliba JB, Vieira L, Fernandes-Cunha GM, et al. Anti-Inflammatory effect of dexamethasone controlled released from anterior suprachoroidal polyurethane implants on endotoxin-induced uveitis in rats. Invest Ophthalmol Vis Sci. 2016;57(4):1671-9.

25. Skaat A, Sagiv O, Kinori M, Ben Simon GJ, Goldenfeld M, Melamed S. Gold micro- shunt implants versus ahmed glaucoma valve: long-term outcomes of a prospective randomized clinical trial. J Glaucoma. 2016;25(2):155-61.

26. Melamed S, Ben Simon GJ, Goldenfeld M, Simon G. Efficacy and safety of gold micro shunt implantation to the supraciliary space in patients with glaucoma: a pilot study. Arch Ophthalmol Chic Ill 1960. 2009;127(3):264-9.

27. Höh H, Grisanti S, Grisanti S, Rau M, Ianchulev S. Two-year clinical experience with the CyPass micro-stent: safety and surgical outcomes of a novel 
supraciliary micro-stent. Klin Monatsbl Augenheilkd. 2014;231(4):377-81.

28. Hoeh H, Vold SD, Ahmed IK, et al. Initial clinical experience with the cypass micro-stent: safety and surgical outcomes of a novel supraciliary microstent. J Glaucoma. 2016;25(1):106-12.

29. Figus M, Lazzeri S, Fogagnolo P, Iester M, Martinelli $P$, Nardi M. Supraciliary shunt in refractory glaucoma. Br J Ophthalmol. 2011;95(11):1537-41.
30. Minckler DS, Francis BA, Hodapp EA, et al. Aqueous shunts in glaucoma: a report by the American Academy of Ophthalmology. Ophthalmology. 2008;115(6):1089-98.

31. Yablonski ME. Trabeculectomy with internal tube shunt: a novel glaucoma surgery. J Glaucoma. 2005;14(2):91-7. 